\title{
A Qualitative Assessment of Health Perceptions in Patients of HIV at a Tertiary Level HIV Clinic
}

\author{
Meha Jain $^{1}$, Anurag Agrawal ${ }^{2}$, Pallavi Bhatnagar ${ }^{3}$, Mamta Yadav ${ }^{4}$
}

\section{ABSTRACT}

It is clearly understood that people address, understand and cope with their health problems with reference to their perception about health and illness. It is in this light that the present study has been taken up to explore the health perception of patients with HIV. The sample consisted of 60 HIV patients- 30 males and 30 females. A major variable was gender. Self designed open-ended questionnaire consisting of 24 items was used. The responses obtained were content analyzed and percentage analysis was done. The results showed that both males and females had poor health awareness. The coping strategies employed by them showed that both males and females feel anxious when they are sick (55\%). Sex stereotype seems to be all pervasive, having effect in the present results as well, with more males reporting rest when sick (26.67\%) as compared to their female counterparts (6.67\%). Poor base of health awareness serves as a stepping stone for creating a preventive intervention package for increasing their health awareness and more positive outlook towards health instead of disease.

Keywords: HIV, Health perception

World Health Organization defined health as "a complete state of physical, mental and social well-being and not merely the absence of disease or infirmity" (World Health Organization, 1948). How one addresses her/his health issues is shaped to a large extent by the health beliefs one carries. Health Belief Model (Hochbaum, 1958) believes that health behaviour depends on two factors: whether the person perceives a personal health threat, and whether the person believes that a particular health practice will be effective in reducing that threat.

Chronic illness is a long lasting condition that can be controlled but not cured like diabetes, hypertension etc. People's reaction and coping to diagnosis of a chronic illness depends on multiple factors like the nature of the illness, the age and resilience of the person as well as

\footnotetext{
${ }^{1}$ Child Psychologist, Department of Pediatrics, I.I.M.S. \& R., Lucknow, UP.

${ }^{2}$ Assistant Professor, Department of Psychiatry, I.I.M.S. \& R., Lucknow, UP.

${ }^{3}$ Professor and Head, Department of Psychology, Lucknow University, Lucknow, UP.

${ }^{4}$ Clinical Psychologist, Department of Psychiatry, I.I.M.S. \& R., Lucknow, UP.

(C) 2015 I M Jain, A Agrawal, P Bhatnagar, M Yadav; licensee IJIP. This is an Open Access Research distributed under the terms of the Creative Commons Attribution License (http://creativecommons.org/licenses/by/2.0), which permits unrestricted use, distribution, and reproduction in any Medium, provided the original work is properly cited.
} 
changes they believe the illness will make in their lives and also how the illness will alter their family and social support.

In the earlier days diagnosis of HIV meant a 'death sentence' but with the discovery of newer effective medications HIV as a chronic illness is widely accepted. The adult HIV prevalence in India has increased to 0.27 percent, as of 2011 (NACO, 2013) and it was estimated that 2.4 million people were living with HIV in India (UNAIDS, 2010). This increase in life expectancy of patients leads them to suffer with not only biological morbidities but also to tackle with multiple social issues like facing stigma, discrimination and refusal of treatment and thus leads to nonparticipation in various treatment strategies. There is lack of knowledge about HIV among the Indian public as well as stigma with the diagnosis of HIV. Results of a study show that $25 \%$ of people living with HIV in India have been refused medical treatment on the basis of their HIV positive status (UNDP, 2006). Furthermore psychosocial factors in the coping of male and female genders are different although both are equally affected with HIV. Diagnosis of HIV infection among women has been shown to result in attribution of blame and labeling in diverse contexts (Bharat et al., 2001). In a study, half of the women respondents ascribed feared in seeking care at a maternity hospital due to bad experiences such as breach of confidentiality, refusal to treat and humiliating statements made by health care staff (Thomas et al, 2005). This stigma causes a lot of people diagnosed with HIV to keep their HIV status a secret.

This grave situation demands change in current management strategies. It is imperative that health policy makers require a proper understanding of the health beliefs and perception of people suffering from HIV as by greater awareness only we would better be able to handle it. More than medical attention psychological support is a basic requisite. Acceptability and awareness are the only ways to fight the virus. Their coping and acceptance regarding the illness is dependent upon their perceptions and belief and proper intervention can be given only if they disclose about their illness. Talking about their illness to somebody who understands of their problem and pain is the first step towards acceptance.

Due to the stigma and discrimination attached with HIV, people suffering from HIV tend to give socially desirable answers. Hence in this area qualitative research is essential to understand perceptions and belief in their context and thereby to identify barriers as well as potential facilitators of changing their health behaviors. Thus, the present study with a qualitative design was undertaken to explore and analyze health beliefs and perceptions of HIV patients in a developing country like India where a mixture of cultural, social, religious and geographical factors affect their health related behaviours as well as coping. 


\section{METHODOLOGY}

The study was conducted from February, 2012 to April 2012 in one of the prominent ART centre of Northern, India. HIV patients having BPL Card, stable on medications, having their illness either in the first or second stage and willing to give informed consent were screened. A total of 60 patients were recruited after taking written informed consent. Males and females tend to have different health perception so the subjects were equally divided into gender to study the differences due to gender. Those subjects having any other terminal illness, neurological disorder and any psychiatric disorder were excluded from the study. The patients were contacted individually by the researcher and information was sought on the questionnaire in two interviews. The initial interview aimed at establishing rapport while responses were taken in the second interview. The patients were continuously motivated to give all the responses coming in their mind and recorded verbatim. It was an exploratory design with an ex-post facto orientation.

\section{TOOLS USED}

Self-designed open-ended questionnaire consisting of 24 items loaded on seven different dimensions was used. These dimensions were:

- Demographic details, Income and adequacy

- Health perceptions (semantic of health, healthy person, semantic of illness, information about ailments)

- Health status (perceived status, health history)

- Coping with personal illness (behavioral level, cognitive level, and financial level)

- Coping with family sickness (experience and cognition)

- Essentials of health

- Satisfaction with life

\section{Scoring and analysis:}

Responses on the self designed questionnaire on health and ailments perceptions were content analysed and percentage analysis on various dimensions was done. 
RESULTS AND DISCUSSION

Table 1: Socio demographic details of HIV patients according to gender

\begin{tabular}{|c|c|c|c|}
\hline & $\begin{array}{l}\text { Females } \\
(n=30) \\
(\%)\end{array}$ & $\begin{array}{l}\text { Males } \\
(n=30) \\
(\%)\end{array}$ & $\begin{array}{l}\text { Total } n=60) \\
(\%)\end{array}$ \\
\hline $\begin{array}{c}\text { Age (years): } \\
25-30 \\
30-35 \\
35-40 \\
40-45 \\
45-50 \\
50-55 \\
55-60 \\
60-65 \\
\end{array}$ & $\begin{array}{l}20 \\
36.67 \\
20 \\
13.33 \\
10 \\
0 \\
0 \\
0 \\
\end{array}$ & $\begin{array}{l}13.33 \\
26.67 \\
23.33 \\
23.33 \\
6.67 \\
0 \\
3.33 \\
3.33 \\
\end{array}$ & $\begin{array}{l}16.67 \\
31.67 \\
21.67 \\
18.33 \\
8.33 \\
0 \\
1.67 \\
1.67 \\
\end{array}$ \\
\hline $\begin{array}{l}\text { Education: } \\
\text { Illiterate } \\
\text { Till } 5^{\text {th }} \\
5^{\text {th }}-9^{\text {th }} \\
10^{\text {th }}-12^{\text {th }}\end{array}$ & $\begin{array}{l}63.33 \\
6.67 \\
16.67 \\
13.33\end{array}$ & $\begin{array}{l}10 \\
13.33 \\
43.33 \\
33.33\end{array}$ & $\begin{array}{l}36.67 \\
10 \\
30 \\
23.33\end{array}$ \\
\hline $\begin{array}{l}\text { Occupation } \\
\text { Agriculture } \\
\text { Business } \\
\text { Labour } \\
\text { Service/job } \\
\text { Pension } \\
\text { Nothing }\end{array}$ & $\begin{array}{l}33.33 \\
6.67 \\
30 \\
20 \\
3.33 \\
6.67 \\
\end{array}$ & $\begin{array}{l}6.67 \\
30 \\
10 \\
36.67 \\
0 \\
3.33 \\
\end{array}$ & $\begin{array}{l}26.67 \\
18.33 \\
20 \\
28.33 \\
1.67 \\
5 \\
\end{array}$ \\
\hline $\begin{array}{l}\text { Income groups (monthly } \\
\text { income) } \\
\text { (Rupees per month): } \\
\text { Below } 1000 \\
1000-2000 \\
2000-3000 \\
3000-4000 \\
4000-5000 \\
\text { Above } 5000 \\
\text { Just enough } \\
\text { No guarantee } \\
\text { Nothing }\end{array}$ & $\begin{array}{l}6.67 \\
36.67 \\
23.33 \\
3.33 \\
6.67 \\
3.33 \\
13.33 \\
0 \\
6.67\end{array}$ & $\begin{array}{l}0 \\
20 \\
20 \\
16.67 \\
23.33 \\
10 \\
0 \\
6.67 \\
3.33\end{array}$ & $\begin{array}{l}3.33 \\
28.33 \\
21.67 \\
10 \\
15 \\
6.67 \\
6.67 \\
3.33 \\
5\end{array}$ \\
\hline $\begin{array}{c}\text { Family size } \\
0-4 \\
4-8 \\
8-12 \\
12-16 \\
\end{array}$ & $\begin{array}{l}20 \\
56.67 \\
20 \\
3.33\end{array}$ & $\begin{array}{l}6.67 \\
70 \\
16.67 \\
6.67 \\
\end{array}$ & $\begin{array}{l}13.33 \\
63.33 \\
18.33 \\
5\end{array}$ \\
\hline
\end{tabular}




\section{Health Perception}

This dimension explored the patients’ perception of health and ailments.

\section{a. Semantics of health}

A painful picture appears where $21.67 \%$ of the patients reported not knowing the meaning of health and out of those who knew, mostly gave personalized responses and health synonyms (18.33\% each). The other categories which appeared were physical strength, causes of health, efficient working with sound mind, absence of disease and good physique, external body.

$33.33 \%$ of the females reported not knowing the meaning of health while there were only $10 \%$ males who could not tell the meaning of health showing significant differences in both. (C.R. = $3.10, \mathrm{p}<0.01$ ). $30 \%$ of the females and $6.67 \%$ males gave personalized response i.e. they talked about their own health. Responses from females were "bahut takleef rehti”, "tension nahi lete" "sehat toh sahi hai" “kamzori toh hai hi, dawa khate hain”. Previous qualitative works have also shown similar findings (Tilak, 2000; Kumari, 2006; Srivastava, 2009).

\section{b. Healthy person}

$35 \%$ of the patients reported that a healthy person is one who has good physical health while $28.33 \%$ of them reported in terms of strong built and personality. This showed that maximum reported in terms of physical health. The other responses included good person, relaxed and happy healthy lifestyle and efficient work. No patient was able to give a complete definition about health and what they understood about healthy person.

$33.33 \%$ females and $36.67 \%$ males reported good physical health essential for a healthy person. The females reported by saying "bukhar na aana”, “beemar na ho", “tabiyat sahi” and the males reported by saying “beemar na ho”, kamzori na ho”, “marz na ho”

$36.67 \%$ of the female patients considered strong built and personality important for a healthy person while only $20 \%$ male patients considered it to be important which was statistically significant (C.R. = 2.02, $\mathrm{p}<0.05)$.

\section{c. Semantics of illness}

In this domain, $38.33 \%$ of the patients gave the names of some specific disease most commonly AIDS and considered it to be life threatening. For another 20\% illness had a personalized meaning that is they talked about their own health. Others defined illness as problem in body part, absence of health while there were others who considered it to be not good or gave causes of illness. Here also 5\% patients reported that they did not know the meaning of illness. 50\% of the females while $26.67 \%$ of the males replied by saying that it was life threatening or gave the name of a specific disease with a significant difference (C.R. $=2.63, \mathrm{p}<0.05$ ). 


\section{d. Information about ailments}

When the patients were asked about the illnesses which they knew 67.94\% patients reported the names of chronic illness and only $28.2 \%$ patients reported the names of seasonal illness. Similar findings have been found in the studies of Kumari (2006) and Srivastava (2009). 8.57\% female patients did not know the name of any ailment while there was no such male patient. This shows limited awareness of the HIV patients about health and illness.

\section{Health Status}

This dimension explored the perception of the patients regarding their present health and their health history.

\section{a. Health status}

Regarding health status, 63.33\% of the patients reported their health to be okay ("abhi theek hai") and only $10 \%$ of them reported it to be good. No significant differences were present between male and female. The patients mentioned that proper treatment was required to keep them healthy so that they could perform daily functions.

\section{b. Health history}

When the patients were asked about the illnesses they had suffered in past $86.67 \%$ of the patients reported to be suffering from a chronic illness like HIV and TB. While there were 06.67\% females who were not aware of their health history, there was no such male.

\section{Essentials of Health:}

This dimension explored the requirements to remain healthy. $78.33 \%$ of the patients considered physical well being like nutritious diet, physical exercise to be an essential for good health. Only 10\% patients talked about mental wellbeing and reported "sakaratmak soch" (positive thinking), tension na karna”, “khush rehna” to be essential. There was no one who talked about social well being.

\section{Satisfaction from Life}

Here the patient's were asked about the kind of life they want in the next birth. $36.67 \%$ of the patients wanted to have a good life and $23.33 \%$ of the patients did not want this disease again (HIV). This shows the devastating nature of the illness. $10 \%$ of the males want to be a good human in the next life as they blame themselves for the disease while there is no such female who desired to be a good human being in the next life.

Now the results pertaining to coping with illness are very briefly discussed.

\section{Coping With Personal and Family Sickness}

This dimension explored the patients' coping strategies about their own illness and family's illness. 


\section{a. Coping at behavioral level}

At the behavioral level, it was seen that $63.33 \%$ of the female as well as the male patients take medicines and visit the doctor. These patients reported “dawa lete hain”, “ilaj karate hain”, “doctor ko dikhate hain" Similar findings have been found in the studies of Kumari (2006), Mishra (2007) and Srivastava (2009). 23.33\% of the females do nothing when they fall sick as they reported "kuch nahi karte hain" $26.67 \%$ of the male patients rest when they fall sick while only $6.67 \%$ women rest when they fall sick this is because the females have to do household work even when they are not well.

\section{b. Coping at cognitive level}

At the cognitive level, 55\% of the patients have anxiety related thoughts for their own health and for the future of their children when they fall sick. From the data it can be seen that more females think about their children as compared to the males. 70\% of the female patients' think about the future of their children and worry about them. On being asked the question they reported "bachhon ka sochte hain", "theek ho jayein warna bachhe anaath ho jayenge”, "bachho ka kya hoga." Others think about the symptoms and money. It is also seen that there are few males (6.67\%) who try to be positive even when they are sick and are suffering from such a chronic illness while there is no female who tries to be positive.

$40 \%$ of the male patients feel anxious when they fall sick. A significant difference (C.R. = 3.29, $\mathrm{p}<0.01$ ) was seen in the responses of females and males.

\section{c. Coping at financial level}

At the financial level $80 \%$ of the patients spend less than Rs.3000, this is because they are getting treated at CSMMU where the medicines are free for them and they only have to make travel expenses.

The coping strategies at the behavioral level are appropriate where the patients visit the doctor when they fall sick. This shows that they take care of their own health.

\section{Coping With Personal and Family Sickness}

Regarding the coping strategies used when any of the patients' family members falls sick, $63.33 \%$ of the patients feel low spirited. Similar findings have been found in the studies of Mishra (2007) and Srivastava (2009).16.33\% of the patients feel anxious when any of the family members gets sick and when children get sick. Others get medications, do nothing or don't think about others. Here a difference is seen in the strategies involved by males and females. 20\% of the males take their sick family member to the doctor while there is no such female. Another difference is also seen wherein $26.67 \%$ females feel anxious while only $6.67 \%$ of the males feel when a family member falls sick. A significant difference $(\mathrm{p}<0.05)$ is seen in the responses of the females and males. 


\section{CONCLUSION}

In conclusion it can be said the HIV patients belonging to the BPL group have incomplete perceptions of health and ailments as they reported physical health in answer to what is health and physical well-being in answer to what is illness.

From the data it is also seen that a difference is seen between females and males in some dimensions. Females gave more personalized responses as compared to males. On the dimension- semantic of health there were $30 \%$ females who gave personalized responses while there were only $6.67 \%$ males who gave personalized responses. Similarly on the dimensionsemantic of illness $26.67 \%$ females gave personalized responses while there were only $13.33 \%$ males who gave personalized responses. A difference is also seen in coping strategies at cognitive level between males and females where females are seen to be thinking about the future of their children at large while only few males were found to be thinking about the future of their children. Regarding the coping of family sickness a difference is seen where $20 \%$ males reported to have taken their sick family member to the doctor while there was no such female who reported this.

Thus it can be seen that a proper understanding of the people suffering from HIV is an important step in planning interventions. Incomplete health awareness and unhealthy coping strategies employed by such patients as evident from the present study highlights the importance of psychological support in such patients. Such support will help them better deal with their pain and anxieties.

Poor base of health awareness serves as a stepping stone for creating a preventive intervention package for increasing their health awareness and more positive outlook towards health instead of disease.

\section{REFERENCES}

Bharat, S., Aggleton, P. \& Tyrer, P. (2001). India: HIV and AIDS-related discrimination, stigmatization and denial. UNAIDS Key material-Best practice collection. Geneva: UNAIDS. www.unaids.org/publications/documents/

Hochbaum, G. (1958). Public participation in medical screening programs(DHEW Publication No. 572, Public Health Service). Washington, DC: U.S. Government Printing Office.

Kumari, Y. (2006) Mental health and rural sector (Unpublished Doctoral dissertation), Department of Psychology, University of Lucknow, Lucknow.

Mishra, N. (2007) Solutions of problems of women of slums of Palia city through social work intervention (Unpublished Doctoral Dissertation) Department of Social Work, University of Lucknow, Lucknow.

NACO (2013). India Annual Report 2012-13 
Singh, M. (2011) Mental health, Quality of life and relational world of slum dwellers (Unpublished Doctoral dissertation), Department of Psychology, University of Lucknow, Lucknow.

Srivastava, A. (2009) Mental health, object relations and quality of life of rural labour (Unpublished Doctoral dissertation), Department of Psychology, University of Lucknow, Lucknow.

Thomas, B.E., Rehman, F., Suryanarayanan, D., Josephine, K., Dilip, M., Dorairaj, V.S., \& Swaminathan, S. (2005). How stigmatizing is stigma in the life of people living with HIV: A study on HIV positive individuals from Chennai, South India. AIDS Care, 17(7), 795-801.

Tialk, S. (2002) towards exploring perception of health and health related problems of and self other relation concepts in slum dwellers (Unpublished Doctoral dissertation), Department of Psychology, University of Lucknow, Lucknow.

UNAIDS (2010) 'UNAIDS report on the global AIDS epidemic'

UNDP (2006), The Socio Economic Impact of HIV and AIDS in India

World Health Organization. (1948). Constitution of the World Health Organization. Geneva, Switzerland: World Health Organization Basic Documents. 